\title{
ME QUEDÉ SIN |
HIJOS
}

Rubén Jaimes Zubieta, Dr. Facultad de Teología Universidad Peruana Unión rubenjaimes@teologia.edu.pe

Fecha de recepción: Mayo 2012 Fecha de aceptación y versión final: Julio 2012

La familia se desarrolla en diferentes ámbitos, tales como el afectivo, social, cultural, religioso y biológico; que están sujetos al cambio debido a inf luencias y circunstancias tanto internas como externas. Entre una de las crisis q ue los padres afrontan está el hecho de ver que sus hijos, por diferentes motivos, abandonan el hogar. A este fenómeno se le conoce como el sindr ome del nido vacio. Este artículo tiene el obje tivo de proveer a los consejer os familiares, los orientadores o mentores de futuras y nuevas familias, el conocimiento de herramientas básicas que les permitan orientar y ayudar a las familias que experimentan específicamente la etapa del nido vacío a reconocer sus problemas y ventajas potenciales, para enfrentar y disfrutar la nueva realidad de esta etapa familiar con actitud asertiva.

Palabras clave: Familia, ciclo vit al, etapa, nido vacio, consejeros familiares. 
Mirá lo que son las cosas, nos vamos quedando solos. Cada rincón de la casa se va muriendo en silencio. Los hijos se hicieron grandes entre penas y alegrias y alrededor de la mesa nos quedan sillas vacias.

Mirá lo que son las cosas, después de los casamientos nos dejan cuartos vacios y fotos para el recuerdo. Imágenes del pasado, una muñeca, un balero, la angustia del primer chirlo, la pena del primer reto. Mirá lo que son las cosas, nos está sobrando casa, nos está sobrando tiempo y aqui hay demasiada calma. Los hijos se fueron yendo, cada uno con su ilusión aunque partieron alegres, hay

pena en mi corazón. Mirá lo que son las cosas, cumplimos nuestro destino el tiempo pasó y ahora estamos como al principio. Yo sé que fue duro a veces, no es fácil criar los hijos pero entre aciertos y errores, mirá qué final más lindo. Mirá lo que son las cosas, ayer domingo vinieron. Cuánto bullicio en la casa y cuánto ruido que hicieron.

La mesa estuvo de fiesta con los hijos y los nietos; Mirá lo que son las cosas, qué pronto que pasa el tiempo.

Argentino Luna, 1997

\section{Definición de familia}

El término familia viene del latín famulus, que significa "conjunto de siervos y dependientes de un jefe o señor" ${ }^{1}$, en referencia a los hijos y la mujer. En general una familia es un grupo de

1 A. Rodríguez, et. al. "Uso de distintos métodos de abordaje de familias: Un relato de la experiencia", en Enfermería integral №. 75 (Septiembre 2006): 13. personas unidas por la consanguineidad y los af ectos filiales, que se constituye mediante derechos y responsabilidades, que es "influenciada socioeconómica y culturalmente por el ambiente/ sociedad en que está incluida" 2 constituyéndose así en la unidad básica de la sociedad.

\section{El Instituto Interamericano} del Niño (IIN), por su par te, establece que la familia,

Es un conjunto de personas q ue conviven bajo el mismo t echo, organizadas en roles fijos (padre, madre, hermanos, etc.) con vinculos consanguineos o no, con un modo de existencia económico y social comunes, con sentimientos af ectivos que los unen y aglutinan. ${ }^{3}$

Suárez presenta algunas def $\mathrm{i}$ niciones instructivas sobre familia, aquí un resumen de es tas ${ }^{4}$ :

\section{Ibíd.}

3 Instituto Interamericano del Niño, "Concepto de familia", Instituto Interamericano del Niño, http://www. iin.oea.org/Cursos_a_distancia/Lectura\%2012_UT_1.PDF (consultado: 03 de julio, 2012).

4 Miguel Ángel Suárez Cuba, "El médico familiar y la atención de la familia", en Revista paceña de medicina familiar 3, No. 4 (2006): 95. 
"Para la Organización Mundial de la Salud (OMS), 'La f amilia es la unidad básica de la organización social' pues 'brinda un entorno social para el desarrollo natural y la realización personal de todos los que forman parte de ella". P ara la sociología es "un grupo social primario de la sociedad", cuyos individuos que la forman le dan "características materiales, genéticas, educativas y afectivas". Desde el punt o de vista de la demografía, la familia se define "por el grado de parentesco dado por el matrimonio consanguíneo o adopción”; de modo que "todas las per sonas que viven bajo el mismo hogar constituyen una familia". En el campo médico, se def ine a la familia como "una unidad de atención médica”, incluy endo a las personas que "conviven en una misma unidad residencial”, unidas por lazos de "dependencia y obligaciones $r$ ecíprocas" y parentesco. En cuanto al concepto sistémico se refiere, la familia es "un sistema social único y primario en permanente interacción con los demás sis temas sociales primitivo y secundario".

Así, en sentido general, se puede entender la familia como un grupo de per sonas unidas, por vínculos matrimoniales o de compromiso, en una relación íntima y personal con sentido de pertenencia e identidad pr opia. Por lo t anto, la $\mathrm{f}$ amilia viene a ser una relación original, con criterios de diferenciación propios, caracterizada por una forma específica de vivir la dif erencia de género (que implica la sexualidad), y las obligaciones entr e las generaciones (que implica el par entesco). Se trata de una relación originaria que se constituye a partir de factores sociológicos autónomos, una relación primordial, que existe desde el origen de la especie humana de modo perdurable constituyendo el principal ámbito de convivencia social del ser humano. ${ }^{5}$

Sin embargo, la cr eencia y práctica de algunos principios bíblicos diferencian la concepción del hogar cris tiano de las concepciones humanistas que se acaban de mencionar. Aunque es necesario ser conscientes del aporte de las ciencias y div ersas investigaciones relacionadas al tema de la $f$ amilia en general, es preciso reconocer que la perspectiva bíblico cris tiana le da una dimensión cósmica a la f amilia.

5 Ibíd, 95-6. 
Tal perspectiva, la que proviene del texto bíblico, permite percibir a la familia desde sus raíces edénicas, instituida por Dios mismo y quien a su vez afirmó: "No es bueno que el ser humano esté solo. Le haré ayuda idónea" (Gn 2:18). Así, la f amilia que se guía por los principios de los diez mandamientos, como lo afirman los esposos Y ounberg, establece su escala de valores del siguiente modo: "Primero Dios (Mandamientos 1-4), luego la familia (5), siguen los demás (69) y por último la atención a las cosas materiales (10)".

La percepción bíblico cristiana de la familia, toma en cuenta el mensaje bíblico para la familia en los tiempos del fin, "el mensaje de Elías" (Mal 4:5, 6) quien restaurará y pr eparará las familias para su encuentro con la familia celestial. También toma en cuenta que la familia es el punto focal del gran conf licto entre el bien y el mal, en cuy o marco se da el último mensaje pr ofético de advertencia de Dios para unir a la familia con Dios y entre sus

6 John y Millie Younberg, Corazones en sintonía con Dios: Guía para mejorar el culto familiar (Buenos Aires: Asociación Casa Editora Sudamericana, 1994), 8. propios miembros antes del inminente fin del mundo. Así, la familia (en particular la cristiana) es un cam po de bat alla decisivo entre las fuer zas cósmicas del bien y del mal, constituyéndose definidamente en el último bas tión de f idelidad a los mandamientos de Dios, el último reducto de obediencia a los principios bíblicos, la última reserva del evangelio e terno y agente salvador de Dios para la raza humana.

\section{La familia como sistema social}

El mundo está formado por una cantidad de macr osistemas y microsistemas, los cuales forman parte de los primer os, además de sus componentes. Existe interrelación dinámica entre ellos y es pr eciso percibir el mundo holísticamente.

Un enfoque sistémico de la familia permite percibir que ésta forma parte de una más am plia (la sociedad) y q ue contienen una más pequeña (sus miembros en f orma individual), de modo que cualquier suceso que afecta a los integrantes que la conforman, en forma particular, así como a la sociedad en la que 
está inmersa, afectando positiva o negativamente a la f amilia. Lo importante en es te aspecto es conservar un balance entr e la modificación constante y la estabilidad perdurable.

Así, es preciso percibir la familia dentro de la iglesia como sistema social, por la signif icación especial que esta tiene debido al trasfondo de cosmovisión cristiana de este enfoque sobre la familia, para finalmente comprenderla dentro de la sociedad como sistema social y la globalidad del mundo en que vivimos. Solamente así será posible comprender su función en la sociedad en que nos desenvolvemos.

De igual modo, Gonzales considera la familia "como un sistema dinámico viviente $\mathrm{q}$ ue está sometido a un continuo establecimiento de r eglas y de búsqueda de acuerdo a ellas". 8 Rodrigues, A. Siva, D. Car valo M. \& Gimenez, por su par te también señalan que un sistema familiar es pues par te de uno

7 Rodríguez, "Uso de distintos métodos de abordaje de familias: Un relato de la experiencia", 13.

8 Juan Max Gonzales Gallegos, "La familia como sistema", en Revista paceña de medicina familiar 4, no. 6 (2007): 111. más amplio (sociedad) y contiene aún otro menor (miembros), cualquier cambio por par te de un miembro molesta a todos o igual puede generar un eq uilibrio entre modificación y estabilidad. ${ }^{9}$

Por lo tanto, un enfoque sistémico de la familia genera conceptos, analogías e instrumentos útiles para el cuidado de la familia, en su objetivo básico de la multiplicación y generación de nuevos individuos para la pr eservación de la sociedad y la especie humana, mediante cuatro propósitos adyacentes:

1. Dar a t odos y cada uno de sus miembros seguridad afectiva.

2. Dar a todos y a cada uno de sus miembros seguridad económica.

3. Proporcionar a la pareja pleno goce de sus funciones sexuales, dando a los hijos la noción firme y vivenciada del modelo sexual, que les permita identificaciones claras y adecuadas.

9 Rodríguez, "Uso de distintos métodos de abordaje de familias: Un relato de la experiencia", 14. 
4. Enseñar r espuestas adaptativas a sus miembros para la interacción social.

Así mismo, Campos, Florenzano y Polanco consideran que

el enfoque para examinar a la familia como sistema integral se apoya más en las relaciones interpersonales que en los individuos mismos aislados, por lo q ue la familia como grupo adquiere una identidad diferente a la de la simple suma de sus componentes. ${ }^{10}$

Pero aunque la familia como sistema es un grupo social q ue constituye una integridad, dicha integridad no se reduce a la suma de las caracterís ticas de sus componentes, de tal modo que no se puede calif icar una familia por el análisis de uno de sus miembros individuales, hay características globales que trascienden las propiedades de sus integrantes.

En resumen, los aspectos que conforman el sis tema familiar son:

10 Nina Horwitz Campos, Ramón Florenzano Urzúa e Isabel Ringeling Polanco, "Familia y salud familiar: Un enfoque para la atención primaria", en Boletín de la Oficina Sanitaria Panamericana 98, №. 2 (1985): 147.
1. El aspect o estructural que da estabilidad a la f amilia, su organización interna o el modo en que interactúan y se vinculan sus integrantes en los subsis temas de la $\mathrm{f} \mathrm{a-}$ milia.

2. El aspecto funcional del sistema, que se nota cuando sus miembros cumplen con sus funciones determinadas en el grupo: la función biosocial, la económica, la cultural y espiritual.

3. El aspecto integrativo del sistema familiar autodirigido, con mecanismos de dir ección que garantizan su integridad y desarrollo.

4. El aspecto social de la $\mathrm{f}$ amilia que la interrelaciona con otros sistemas. En tal sentido, la familia es un sis tema abierto que intercambia energía e inf ormación con su medio.

En este sentido, es correcto afirmar que la familia constituye la célula básica de la sociedad. Debido a esto, es entonces posible entender que la familia constituye un microsistema funcional sujeto a le yes y normas que responden a las necesidades 
internas del grupo y a su vez reflejan la realidad externa de la sociedad. Así, la sociedad, la familia y el individuo se inf luyen y condicionan recíprocamente.

\section{Ciclo vital de la familia}

Aunque algunos autores cuestionan la validez analítica del concepto de ciclo vit al de la familia porque deja fuera eventos como el divorcio, segundas nupcias, mortalidad inf antil o la experiencia de un traslape cuando nace un hijo después que el mayor abandonó el hogar, recomendando procedimientos nuevos de in vestigación, todavía se reconoce el valor del concep to tradicional del ciclo vit al de la familia para el desarr ollo de la disciplina. ${ }^{11}$

El IIN menciona que la familia pasa por las siguientes etapas en su ciclo vit al: "nacimiento, crecimiento, multiplicación, decadencia y trascendencia”.

11 Félix Acosta, "La familia en los estudios de población en América Latina: Estado del conocimiento y necesidades de investigación", en Papeles de población, No. 37 (julio- setiembre, 2003): 14-7.

12 Ariel Gustavo Forselledo y Virginia Esmoris Sbárbaro, "Consumo de drogas y familia: Situación y factores de riesgo", Instituto Interamericano del
Durante dicho proceso o ciclo vital de vida, la $\mathrm{f}$ amilia cumple con sus funciones $t$ anto nutritivas como normativas, con el objetivo ulterior de generar nuevos individuos a la sociedad. Durante ese proceso de desarrollo, las $\mathrm{f}$ amilias se es tructuran de muchas y diferentes formas, teniendo como extremos a las familias piramidales por un lado y a las familias consensuales o circulares por el o tro, de acuer do al modelo de su comunicación y ejercicio de poder.

Un estudio del ciclo vital de la familia o las e tapas de vida familiar como unidad básica de la sociedad, o "célula fundamental de la sociedad" ${ }^{13}$ permite reconocer que la etapa en la que la pareja experimenta la partida de los hijos del círculo familiar para quedarse nuevamente solos como al principio, ha sido denominado como la etapa del nido vacío.

Durante dicho ciclo vital los miembros de la familia van atravesando por diferentes momen-

Niño, http://www.iin.oea.org/Cursos_a distancia/Lectura\%2011_UT_1.p df (consultado: 03 de julio, 2012).

13 Rodríguez, "Uso de distintos métodos de abordaje de familias: Un relato de la experiencia", 14. 
tos en su desarr ollo individual, así como en su unidad $f$ amiliar como grupo. A medida q ue crecen sus miembros, la familia también debe cr ecer saludablemente en su conjunto. Pero si en dicha etapa la familia no se acomoda a las diferentes exigencias del desarrollo de sus miembros, probablemente experimentarán diversas dificultades y disfunciones.

\section{Los hijos en la familia}

Una etapa fundamental durante el ciclo vit al individual y grupal de la familia es cuando la pareja procrea. A partir de allí, cada miembro que conforma la familia "atraviesa por varias e tapas determinadas que van desde el nacimiento hasta la madurez y la muerte. Tanto desde un punto de vista biológico como psicosocial, cada una de es tas etapas tiene características que la individualizan" y estas etapas tienen las siguientes caracterís ticas, 14 presentadas en la Tabla 1.

En tales momentos, los ciclos vitales de cada individuo se engranan con los de o tros miem-

14 Horwitz, "Familia y salud familiar: Un enfoque para la atención primaria", 147. bros de su familia y conforman el ciclo vital familiar. Durante esa etapa de formación y desarrollo individual y familiar que va desde la formación de la amis tad (enamoramiento) pasando por el noviazgo y matrimonio, cada miembro de la familia aporta en la formación de la nueva familia todo aquello que ha aprendido, vivido y experimentado en su familia de origen.

Pero entonces llega la e tapa cuando cada hijo debido a su propio desarrollo y dif erenciación tiene que alejarse del hogar para emprender su propio ciclo vital dejando a su $\mathrm{f}$ amilia originaria, quedando así el hogar de los padres y esposos como un nido vacío.

\section{Cuando los hijos se van}

En efecto, las $\mathrm{f}$ amilias después que se cons tituyen pasan por diversas etapas, que con respecto a los hijos pueden ser : la etapa de los hijos peq ueños (preescolar), la e tapa de los hijos en edad es tudiantil (niñez, adolescencia y juventud), y luego la e tapa de los hijos adult os independientes, "momento" cuando los hijos (ahora adult os jóvenes), han creado sus propios compromisos e inter eses fuera 


\section{Tabla 1. Etapas del ciclo de vida}

\begin{tabular}{|l|l|}
\hline Ecad: & Desarrollo \\
\hline Infancia & A dquisición de una confianza básica \\
\hline Niñez temprana & A dquisición de sentido de la autonomía \\
\hline Edad del juego & A dquisición de un sentido de iniciativa \\
\hline Edad escolar & A dquisición de un sentido de industria \\
\hline A dolescencia & A dquisición de un sentido de identidad \\
\hline A dulto Joven & A dquisición de un sentido de intimidad y solidaridad \\
\hline A dultez & A dquisición de productividad biológica o social \\
\hline M adurez & A dquisición de un sentido de integridad. \\
\hline
\end{tabular}

del hogar: amigos, una carr era, un trabajo y en muchos casos casados, con una pareja con la que comparten su vida.

En esta nueva e xperiencia de organización f amiliar, la relación es entre adultos, quienes, según la Agintzari S. Cooperativa de Iniciativa Social, han de ir renegociando explícita o implícitamente el nuevo modo de relacionarse y convivir, mediante las siguientes tareas ${ }^{15}:$ 1) Favorecer

15 Agintzari S. Cooperativa de Iniciativa Social, "El ciclo vital de la familia", Agintzari S. Coop. de Iniciativa Social, http://www.gurasoena.org/documentoTemas/ 070104210320071715060015. pdf (consultado: 03 de julio, 2012). el proceso de sana independencia y emancipación de los hijos adultos. 2) Generar un $r$ eencuentro entre los cónyuges para afrontar las nuevas dif icultades de la e tapa de "nido vacío". 3) Renegociar nuevas pautas entre ambos cónyuges para apo yarse mutuamente en es ta transición al "nido vacío", intentando que esta sea lo menos traumática posible. El subsis tema conyugal es de nuevo el pilar fundamental de la familia. 4) Asumir es ta nueva etapa como una etapa de desarrollo para los cónyuges que quedan solos. Desarrollo individual y de pareja en un momento en que ya no deben dedicarse a la crianza de los hijos. 


\section{El nido vacío}

La etapa del nido vacío corresponde al momento de la par tida de los hijos del hogar donde han sido criados por sus padres, apartándose de estos para empezar su propio ciclo de vida. Los hijos normalmente tienden a independizarse y crear su propio hogar, y cuando el último hijo deja a la $f$ amilia se produce la situación del nido vacío.

Toda familia debe per cibir desde el nacimiento de los hijos, que estos algún día madurarán, se independizarán y em pezarán su propia familia con su propio ciclo vital. Todo es cuestión de tiempo, ellos se harán jóv enes adultos, se independizarán y dejarán la familia, lo cual requiere planificación y preparación de la familia para afr ontar con éxit o los desafíos de dicha etapa.

Algunos padres pueden vivenciar positivamente esta etapa, porque les ofr ecerá cierta libertad y sensación de menos responsabilidad con la crianza de los hijos. Otr os en cambio lo verán como una amenaza por algunos factores negativos como la soledad, q ue traerá consigo la depresión y remordimientos, por no haber pasado más tiempo con los hijos.

Pero a pesar del síndrome del nido vacío, los padr es seguirán siendo padres, de modo que harían bien en tomar en cuenta una serie de factores que pueden ser de utilidad para afrontar con éxito dicha etapa de ciclo f amiliar.

Echerri citando a Lazarus, menciona algunos $r$ ecursos sicológicos de afr ontamiento que pueden resultar de utilidad para enfrontar la etapa del nido vacío: ${ }^{16}$

1. Salud y energía. Elementos de carácter físico y biológico que pueden predisponer positivamente a la hora de enfrentar el suceso.

2. Cosmovisión positiva y optimista. Amplia socialización, esfuerzo en el logro de metas, ser op timistas ante los retos de la vida, seguridad al enfrentarlos. Esto incluye el

16 Danny Echerri Garcés, "El nido vacío: Una propuesta de intervención", Interpsiquis $2010,11^{\circ}$ Congreso Virtual de Psiquiatría, http://www.psiquiatria. $\mathrm{com} /$ bibliopsiquis/bitstream/10401/101 2/1/25cof445275.pdf (consultado: 03 de julio, 2012). 
autoconcepto, la autovaloración positiva y una concepción clara del mundo.

3. La habilidad para la r esolución de problemas.

4. Habilidades sociales. Capacidad de es tablecer relacionamientos positivos, saber escuchar, comprender, ser empáticos, buena comunicación.

5. Redes de apoyo social. Grupo humano de apoyo al cual puede acudir un suje to cuando tiene problemas vivenciales.

6. Recursos materiales, como estabilidad económica, alimentación, región, transporte, estilo de vida, entre otros.

El punto dos parece ser especialmente significativo pues se trata de tener una filosofía de la vida, una causa superior y trascendente en la cual creer y por la cual vivir, como precisamente lo tienen las familias cristianas.

\section{Empezamos de a dos y terminamos de a dos}

Me casé con Lucy a los 23 años (ella con 22), pasamos por todas aquellas etapas del matrimonio descritos por la Organización Mundial de la Salud (OMS). ${ }^{17}$ Las distintas etapas de desarrollo de la familia han sido caracterizadas mediante dis tintas clasificaciones, pero la OMS las divide en seis etapas evolutivas. Estas etapas se han adap tado para presentarlas a modo de testimonio vivo del propio ciclo vital del autor de este artículo.

\section{Formación del matrimonio}

Después de un año de relacionamiento de amis tad, empezamos una etapa de noviazgo con el conocimiento y el permiso de nuestros padres. Nuestro relacionamiento se hizo perdurable y entonces decidimos casarnos y empezar nuestro proyecto de vida juntos. Esto estableció una serie de dependencias cualit ativamente distintas de cualquier otro vínculo existente.

Aprendí que la elección libre de mi esposa implicaba reciprocidad pues elegí y fui elegido. Esto

17 Ingrid Vargas, "Familia y ciclo vital familiar", Facultad de Medicina: Departamento de Psiquiatría y Salud Mental de la UNAM, http://psiquiatria.facmed.unam.mx/doctos/descargas $/ 4.1 \% 20$ CICLO $\% 20$ VITAL $\% 20$ DE\%20LA\%20FAMILIA.pdf (consultado: 03 de julio, 2012). 
se podía notar por el enamoramiento mutuo, por el equilibrio personal y de par eja que inició nuestra madurez emocional, interpersonal, social y laboral para un buen desempeño conyugal.

\section{Nacimiento de primero al cuarto hijo.}

Esta etapa nos tocó vivir desde el segundo al noveno año de matrimonio. El nacimiento de los hijos provocó cambios radicales en nuestra relación de pareja y en el relacionamiento de ambas familias. Se r edefinió mi r elación que antes era de dos a seis personas. Esto afectó mi rol y el de mi esposa, por que ahora teníamos que cumplir nuestro rol no solo de esposos sino de padres. Mis padres y suegros, por su parte, de padres pasaron a su nuevo rol de abuelos.

Durante este periodo no té que la $r$ elación madre-hijo es más fuerte que la relación padrehijo. Esto se debe a que la madre es la que lo tiene en su regazo, lo alimenta y pasa más tiempo con el hijo. El padr e poco a poco recupera su relación con su esposa y asume su papel de padr e con sus hijos conectándolos más con el mundo exterior. En es ta etapa también experimentamos la formación escolar y educativa de nuestros hijos, su r elacionamiento con personas fuera de la familia. Durante este tiempo mi esposa pudo trabajar para apoyar a la economía de la familia.

De igual modo, su inclusión y su r elacionamiento con los miembros de la Iglesia A dventista del Sép timo Día (IASD), iglesia a la cual nues tra familia pertenece, favoreció mucho al desarrollo integral de la f amilia y su integración social.

Esta época también trajo los problemas de la adolescencia y las crisis de r elacionamiento familiar, que felizmente los superamos gracias a la madur ez del desarrollo equilibrado de la f amilia.

\section{Extensión inicial cuando se casan los hijos.}

Esta etapa consistió en las primeras salidas de hogar por parte de nuestro primer hijo en pos de sus es tudios fuera del país y de nuestra hija por su matrimonio. Pero como teníamos dos hijas más es ta experiencia no fue tan traumática. Esta experiencia también significó algunos cam- 
bios de roles y funciones. La madre (mi esposa) tuv o que viajar para visitar tanto a mi hija en su nuevo hogar, como a mi hijo fuera del país. Además tuvimos que aprender a reconocer a la nueva familia de mi hija como diferente, con caracterís ticas propias, creando entonces nuevas formas de interrelación familiar.

\section{Extensión completa cuando todos los hijos se casan y salen de la familia.}

Esta etapa no la hemos completado aún. Es tamos experimentando los primer os síntomas, pues mi t ercera hija ya se ausentó de la familia por motivos de trabajo y ahora viv e en o tra ciudad. Sin embargo nuestra última hija aún estudiará dos años más y vivirá con nosotros, lo que permite que sigamos cumpliendo nuestro rol como padres, que ya dura 31 felices años.

\section{Contracción cuando mi última hija abandone el hogar.}

Esta etapa la experimentaremos en algunos años más y debemos prepararnos para ese momento. Pero mi esposa con "sabia intuición" ya hace planes para nuestra vida durante esa etapa cuando definitivamente me quede sin hijos y mi nido quede vacío. Sin embargo te nemos claros modelos de cómo afrontar esta etapa en las e $\mathrm{x}$ periencias de nues tros padres, quienes ya no tienen a los hijos bajo su techo.

\section{Contracción completa muerte del primer cónyuge.}

Aún no hemos visto esto en el caso de mis padres ni suegros. Pero sospechamos que debe ser traumático.

\section{Disolución muerte del cón- yuge sobreviviente.}

Llegará el momento cuando el hogar que se formó primero de mis padr es y luego el mío desaparecerá y t odo será solo recuerdos y memorias. Solo espero que hayamos dejado un legado positivo para la $\mathrm{f}$ amilia que sobreviva, para la IASD y la sociedad.

\section{Conclusión}

La familia, a lo largo de su ciclo vital tiene que enfrentar numerosas situaciones que pueden afectar su desarrollo, tales como 
la pobreza, enfermedades, crisis y conflictos producidos por los cambios propios de las e tapas del ciclo de vida. $\mathrm{P}$ ara dichas circunstancias es necesario estar preparado. Solo así se podrá r ecuperar el equilibrio y el balance para continuar hacia una me ta trascendente que dejar solo un legado para esta vida, sino para la vida eterna en unión con las familias redimidas por Jesús.

Las familias pueden cont ar con recursos que favorecen su adaptación a las contingencias del ciclo de vida. Incluso, los sucesos negativos pueden ser aprovechados como parte del apren102 dizaje para obtener actitudes y acciones asertivas de par te de los miembros de la familia ante cualquier desafío q ue se pr esente durante el paso por cada etapa del ciclo de la vida. Así, especialmente durante la etapa del nido vacio, se precisa que las necesidades sociales básicas de la familia, sean satisfechas a través de la interacción con o tros, en especial de la red social en la que está inmersa. Un ambiente social importante para este proceso es la iglesia, además de los recursos propios de su red fami- liar, sean es tas necesidades de carácter financiero, emocional, educativas y de inf ormación, manejo médico y espiritual.

La etapa de nido vacío, en la que los hijos se van y forman sus propias familias, puede ser una oportunidad perfecta para que la pareja se reencuentre nuevamente. Después de vivir las e tapas anteriores con satisf acción, experimentarán un encuentr o emocional, renovarán su r elación física y emocionalmente, compartirán su tiempo e intereses comunes; se dedicarán a apoyarse mutuamente y protegerse para vivir una vida abundante y acompañarse en la vejez.

Es también cierto que puede haber un rompimiento afectivo que crea una distancia de intereses mutuos; sensación de vacío y pérdida del sentido de vida, lo que impedirá que la v ejez sea una etapa agradable. Por lo tanto, es pr eciso conocer el ciclo vital de la f amilia, saber en qué etapa se encuentra nues tra familia para llevarla por el camino del auténtico amor y respeto mutuo no sólo en esta vida sino en la eternidad. 